\title{
Strategi Promosi Penyelenggaraan Wisata Outbound Dalam Meningkatkan Kunjungan di Taman Agro Wisata Bukit Naang Kabupaten Kampar
}

\author{
RISNAYANTI \\ \& \\ YUTIA FEBRISA
}

Dosen Sekolah Tinggi Pariwisata Riau

\begin{abstract}
In promoting the attraction Agro Tourism Park Hill Naang as outbound tourism in Kampar, the strategy undertaken by the manager of Agro Wisata Taman Bukit Naang among others: Hold exhibitions and distribute brochures to visitors; By using print, electronic, social media and blogs; Information from mouth to mouth. There are some things that become obstacles for management Taman Bukit Naang Agro Tourism Kampar district in conducting kepromosiannya, namely: Lack of funds for promotion; The time is not right to conduct a campaign; The absence of public transport that passes through the causeway to the vehicle in Taman Bukit Naang Agro Tourism; Less passage of the campaign carried out; Not its precise target promotion undertaken. The work done by the manager of Agro Tourism Park Hill Naang in Kampar regency in mengetasi problems were found in outbound tourism in an effort to promote it, namely: Improving the service that is provided by the board and employees in Taman Bukit Naang Agro Tourism; Hold a public transport that will pass between the causeway to enter the vehicle Taman Bukit Naang Agro Tourism.
\end{abstract}

Keywords: Promotion Strategy, Outbound Tourism, Agro Tourism Park Hill Naang

\section{PENDAHULUAN}

Taman Agro Wisata Bukit Naang telah memiliki fasilitas outbound dan Adventure. Luas lahan Taman Agro Wisata Bukit Naang 80 Ha, sejak di buka untuk umum tahun 2008 lalu, berbagai instalasi telah memanfaatkan Taman Agro Wisata Bukit Naang untuk outbound, berkemah, racing dan kegiatan petualangan lainya. Taman Agro Wisata Bukit Naang memiliki fasilitas kolam renang, tree top, trampoline perkemahan, water boom, lokasi tracking, arena ATV, arena pointball dan suasana alami dikelilingi pesona alam yang tidak pernah di temui di belahan daerah lain di Riau.

Saat ini Taman Agro Wisata Bukit Naang memiliki 17 fasilitas outbound dan petualang. Salah satunya adalah Flying fox sepanjang $540 \mathrm{~m}$, dan merupakan flying fox terpanjang se Indonesia yang terhubung dengan fasilitas tree top lainnya. Untuk membangun fasilitas ini, pemiliknya yang bernama Djuharman Arifin mendatangkan konsultan asal perancis Christofer Jorand. Di Indonesia saat ini hanya memiliki 5 tree top, yakni di Bali, Banyuwangi, Semarang, Ancol Jakarta, dan Bukit Naang Kabupaten Kampar. Banyaknya wisatawan yang berkunjung ke Taman Agro Wisata Bukit Naang karena mereka tertarik dengan wahana outbound yang ada di Taman Agro Wisata Bukit Naang, karena itu terjadi peningkatan wisatawan yang berkunjung ke Taman Agro Wisata Bukit Naang.

Terjadi peningkatan kunjungan dari tahun 2009 sampai dengan tahun 2011, tetapi di tahun 2010 jumlah pengunjung yang datang ke Taman Agro Wisata Bukit Naang berkurang hinggal $22 \%$. Penurunan terjadi disebabkan oleh banyak faktor, kemungkinan faktornya adalah 
kurangnya promosi yang di lakukan oleh pihak pengelola Taman Agro Wisata Bukit Naang. Pada tahun 2011, kenaikan jumlah pengunjung bertambah di Taman Agro Wisata Bukit Naang tetapi belum tercapai dari target yang di tetapkan oleh pihak pengelola yaitu 250.000 sampai dengan 300.000 orang pertahunnya. Untuk itu pihak pengelola Taman Agro Wisata Bukit Naang melakukan strategi promosi dalam meningkatkan kunjungan di Taman Agro Wisata Bukit Naang, penulis tertarik untuk melakukan penelitian disebabkan karena Taman Agro Wisata Bukit Naang merupakan kawasan yang sangat potensial bila akan dikembangkan sebagai vintage point. Taman Agro Wisata Bukit Naang juga merupakan satu - satunya objek wisata di provinsi Riau yang mengemukakan konsep adventure dan outbound yang menjadi daya tarik berbeda.

Sebagai kerangka pemikiran dalam penulisan, perlu adanya landasan teori yang mendukung, sehingga materi yang disampaikan memiliki dasar-dasar pegangan. Berikut beberapa teori yang ada kaitannya dengan permasalahan yang dibahas sebagai acuan dan pedoman dalam penelitian. Oka A Yoeti $(1999 ; 109)$ mengintrepetasikan pariwisata adalah salah satu perjalanan yang dilakukan untuk sementara waktu dari suatu tempat ke tempat lain dengan maksud bukan untuk berusaha bisnis atau mencari nafkah di tempat yang di kunjunginya tetapi semat-mata untuk bensenang-senang dan mengis waktu luang untuk menikmati perjalanan.

Pariwisata menurut Nyoman S.Pendit $(2002 ; 26)$ adalah kepergian orang-orang dalam jangka waktu pendek, sementara, ke tempat-tempat tujuan di luar tempat tinggal dan bekerja sehari-harinya serta kegiatan-kegiatan mereka selama berada di tempat-tempat tujuan tersebut untuk berbagai motivasi asal usaha mereka tidak mencari nafkah. Selanjutnya menurut Happy Marpaung $(2002 ; 13)$ wisatawan adalah orang yang mengadakan perjalanan dari tempat kediamannya tanpa menetap di tempat yang didatanginya, atau hanya untuk sementara waktu tinggal di tempat yang didatanginya.

Mereka dikatakan wisatawan karena Orang-orang yang sedang mengadakan perjalanan untuk bersenang-senang, untuk keperluan pribadi, kesehatan dan sebagainya. Orang-orang yang sedang mengadakan perjalanan untuk maksud menghadiri pertemuan, konferensi musyawarah , atau didalam hubungan sebagai badan / organisasi (ilmu pengetahuan, administrasi, diplomatik, olahraga, keagamaan, dan sebagainya). Orang-orang yang sedang mengadakan perjalanan dengan maksud bisnis. Pejabat pemerintah dan orang-orang militer beserta keluarganya yang diposkan di suatu Negara lain hendaknya jangan dimasukkan dalam kategori ini tetapi apabila mereka mengadakan perjalanan ke negeri lain, maka hal ini dapat digolongkan sebagai wisatawan.

Pemasaran pariwista merupakan kegiatan yang bertujuan untuk memperkenalkan produk pariwisata. Meliputi sejumlah kegiatan yang maksudnya untuk mempengaruhi, menghimbau, dam membujuk wisatawan potensial sebagai konsumen agar mengambil kepiutusan untuk mengadakan perjalanan. Pemasarn diartikan sebagai suatu reorientasi kebijakan usaha dan suatu pembenahan total dalam pemikiran-pemikiran dasar dan penerapannya dalam organisasi atau badan usaha. Adapun tujuan dari pemasaran pariwisata Salah Wahab, (2000;150) adalh untuk memikat dan meyakinkan wisatawan bahwa daerah tujuan wisata yang tersedia dengan daya tarik, fasilitas, dan jasa-jasanya akan memenuhi selera mereka untuk datang.

Salah Wahab $(2000 ; 79)$ merumuskan pengertian pemasaran pariwisata sebagai proses manajemen dimana Organisasi Pariwisata Nasional (OPN) atau perusahaan kepariwisataan mengidentifikasikan wisatawan pilihan mereka, baik aktual maupun potensial, berkomunikasi dengan mereka untuk meyakinkan dan mempengaruhi keinginnan, kebutuhan, motifasi, kesenangan, maupu ketidak senangan mereka pada tingkat lokal, regional, nasional, maupun 
internasional, dan menyesuaikan produk wisatan mereka sesuai situasi agar wisatawan puas dengan memenuhi keinginan mereka.

Selanjutnya menurut Wahab $(2000 ; 109)$ pemasaran pariwisata di tandai oleh 3 ciri utama: Merupakan penawaran jasa-jasa. Dengan demikian apa yang ditawarkan itu tidak mungkin ditimbun dan harus dimanfaatkan dimana produk itu berada. Dengan kata lain mustahil mengangkatnya, dan oleh sebab itu produk tersebut berbeda dari produk-produk yang lain ditawarkan. Yang ditawarkan itu sifatnya kaku (frigid), dalam arti bahwa dalam usaha mengadakannya untuk keperluan wisata, sulit sekali untuk mengubah sasaran penggunaannya di luar pariwisata. Karena pariwisata belum menjadi kebutuhan pokok manusia, maka penawaran pariwisata harus bersaing ketat dengan penawaran barang-barang dan jasa-jasa lain.

Menurut Richard Sihite $(2000 ; 110)$ ada 5 kategori utama dari hasil karya buatan manusia yang bisa di tawarkan dalam pemasaran Pariwisata, antara lain: Yang berciri sejarah, Budaya dan Agama; Sarana dan prasarana; Sarana pencapaian dan alat komunikasi penunjang; Sarana pelengkap; dan Pola hidup masyarakat. Selanjutnya menurut Salah Wahab (2000;15), pemasaran pariwisata dapat dilakukan melalui penyebaran informasi, antara lain: Periklanan; Brosur, buku panduan; Film; Poster, pamphlet; Surat kabar dan sebagainya.

Objek wisata menurut Mardiyatama (2006;52) adalah sesuatu yang menjadi pusat daya tarik wisatawan, dan dapat memberikan keputusan pada wisatawan. Hal yang dimaksud dapat berupa; 1) yang berasal dari alam, misalnya pantai, pemandangan alam, pegunungan, hutan, dan lain-lain, 2) yang merupan hasil budaya, misalnya museum, candi, galeri, 3) yang merupakan kegiatan, misalnya kegiatan masyarakat keseharian, tarian, karnaval, out bound, dan lain-lain. Objek wisata bersifat statis, yakni cara penjualannya di tempat, tidak dibawa pergi.

Menurut Richard Sihite (2000;152), bahwa di dalam Pembangunan Pariwisata, objek dan daya tarik wisata merupakan sasaran atau fokus utama, karena: Yang menjadi penyebab utama wisatawan mengunjungi suatu tempat. Dalam pembangunannya berdasarkan orientasi berfokus dan terpadu. Ketepaduannya adalah dengan membangun sarana dan juga prasarana yang berhubungan dengan daya tarik objek wisata tersebut, baik akomodasi, trasportasi, dan lain-lain. Sarana kepariwisataan yaitu semua bentuk yang dapat memberikan pelayanan kepada wisatawan.

Menurut Smith $(2004 ; 58)$ yang perlu di perhatikan dan dikerjakan dalam pengemnbangan pariwisata yang baik, yaitu : Pembanguna kawasan pariwisata. Pemasaran pariwisata, Kebutuhan wisatawan. Bauran pemasaran menurut Bashu Swastha (2001;42) adalah kombinasi dari 4 variabel atau kegiatan yang merupakan inti dari sistem pemasaran perusahaan, yakni produk, stuktur harga, kegiatan promosi, dan sistem distribusi.

Promosi menurut kamus Oxford Advanced Learner's Dictionary (AS Hornby) adalah Pertama ; Kegiatan yang dilakukan untuk meningkatkan penjualan suatu produk atau jasa. Kedua ; Kegiatan yang dilakukan untuk mendorong orang percaya terhadap nilai suatu barang. Menurut Bashu Swastha $(2001 ; 345)$ promosi adalah suatu arus informasi atau persuasi suatu arah yang dibuat untuk mengarahkan seseorang atau organisasi kepada tindakan yang menciptakan pertukaran dalam pemasaran.

Menurut Bilson Simamora $(2001 ; 32)$ promosi yaitu kegiatan-kegiatan untuk mengkomunikasikan kelebihan-kelebihan produk dan membujuk konsumen untuk membelinya. Sedangkan Siswanto Sutojo (2001;12) mengemukakan promosi sebagai kegiatan memperkenalkan produk, kemudian meyakinkan serta mengingatkan konsumen akan manfaat produk dengan harapan tergerak hati mereka secara suka rela untuk membeli produk tersebut. Promosi juga berkaitan dengan upaya untuk mengarahkan seseorang agar dapat mengenal 
produk, perusahaan, lalu memahaminya, berubah sikap, menyukai, yakin, kemudian akhirnya membeli dan selalu ingat akan produk tersebut (Fandi Tjiptono (2002;222).

Promosi merupakan sebuah aktifitas menawarkan produk atau jasa yang bertujuan menarik orang lain untuk membeli, menggunakan, mengunjungi, walaupun hanya melirik produk atau jasa barang yang ditawarkan (http;//www.didatstriadi web blog/page 232/2007). Henry Simamora $(2001 ; 755)$ menjelaskan promosi yaitu perencanaan, penerapan dan pengendalian komunikasi dari sebuah organisasi kepada pelanggan dan pemirsa sasaran lainnya. Sedangkan strategi promosi yaitu memadukan periklanan, penjualan pribadi, promosi penjualan, dan publisitas ke dalam sebuah program yang terkoordinasi untuk berkomunikasi dengan para pembeli dan pihak lainnya yang mempengaruhi keputusan pembelian.

Strategi promosi merupakan tindakan-tindakan perencanaan, implementasi dan pengendalian komunikasi organisasi kedapa pelanggan dan audiens (Target Audience) lainnya. (C.M Lingga Purnama,2001;150). Menurut Assauri Sofyan (2000;240) promosi adalah usaha perusahaan untuk mempengaruhi dengan merayu (persuasive communication) calon pembeli melalui pemakaian segala unsur acuan pemasaran. Promosi juga sering dikatakan sebagai proses berlanjut karena dapat menimbulkan rangkaian kegiatan selanjutnya dari perusahaan. Oleh karena itu promosi dipandang sebagai arus informasi atau persuasi satua arah yang dibuat untuk mengarahkan seseorang atau organisasi kepada tindakan yang menciptakan pertukaran dalam pemasaran. Inti dari kegiatan promosi adalah suatu bentuk kegiatan komunikasi pemasaran yang berusaha untuk menyebarkan informasi, mempengaruhi, mengingatkan pasar sasaran agar bersedia menerima, membeli dan loyal pada produk yang ditawarkan oleh perusahaan yang bersangkutan (Ali Hasan, 2008;367).

\section{METODE}

Metode yang dipakai dalam penelitian penulis mencakup metode pengumpulan data dan metode analis. Sampel dalam penelitian ini adalah satu orang pemilik Taman Agro Wisata Bukit Naang, 21 orang pengurus dan karyawan Taman Agro Wisata Bukit Naang, dan 50 orang pengunjung Taman Agro Wisata Bukit Naang. Dalam analisa ini, penulis menggunakan metode deskriptif yaitu suatu cara menganalisa data yang sudah ada dengan menggunakan sistem tabulasi dan dihubungkan dengan keadaan yang sebenarnya serta dirangkai dengan teori - teori yang mendukung pembahasan masalah tersebut.

\section{HASIL}

\section{Strategi Promosi Penyelenggaraan Wisata Outbound Dalam Meningkatkan Kunjungan di Taman Agro Wisata Bukit Naang Kabupaten Kampar.}

Pengelola Taman Agro Wisata Bukit Naang Kabupaten Kampar sangat berperan dalam melakukan strategi promosi untuk menjadikan Bukit Naang sebagai wisata Outbound terpopuler di Riau . upaya yang dilakukan oleh pengelola yang bekerjasama dengan pemilik dan karyawankaryawan yang bekerjadi Taman Agro Wisata Bukit Naang yaitu ;

\section{Mengadakan Pameran}

Melakukan upaya seperti mengadakan pameran pariwisata outbound yang pernah di lakukan Riau expo Pekanbaru bekerjasama dengan Riau Tourism Board sejak tahun 2009 sampai dengan 2012 ini. Disamping itu, brosur juga di bagikan kepada pengunjung.

\section{Menggunakan Media Cetak dan Elektronik}


Selain mengadakan pameran dan membagikan brosur kepada pengunjung, upaya yang dilakukan untuk meningkatkan kunjungan di Taman Agro Wisata Bukit Naang sebagai wisata outbound yaitu dengan menggunakan media cetak seperti Riau Post, Tribun, dan media elektronik seperti, Riau TV, TVRI Riau dan lain-lain. Sehingga Bukit Naang akan di kenal sebagai tempat wisata outbound terbaik di Riau

\section{Dari Mulut ke Mulut}

Upaya lain yang sangat besar pengaruhnya untuk meningakatkan kunjungan di Taman Agro Wisata Bukit Naang sebagai wisata outbound agar dapat di kenal yaitu dari mulut ke mulut. Dimana upaya ini lebih dapat tersebar sehingga pengunjung tidak ragu lagi untuk datang mengunjungi dan menikmati pemandangan asri yang ada di Bukit Naang dan bermain permainan outbound yang telah di sediakan.

\section{Internet}

Internet merupakan teknologi baru yang sekarang sangat diminati oleh pelaku promosi dalam memperkenalkan produk mereka. Tapman Agro Wisata Bukit Naang menggunakan fasilitas internet diantaranya adalah sosial media seperti Facebook (Bukit Naang Kabupaten Kampar), tweeter (@bukitnaang_kampar), blog (http://bukit-naang.blogspot.com) dan email (bukitnaang@yahoo.com) Dengan menggunakan kemudahan yang di berikan masyarakat akan lebih mudah mengetahui tentang Taman Agro Wisata Bukit Naang sebagai wisata outbound.

\section{Faktor Penghambat dan Cara Untuk Mengatasi Hambatan Meningkatkan Kunjungan di Taman Agro Wisata Bukit Naang sebagai Wisata Outbound}

Didalam mempromosikan Taman Agro Wisata Bukit Naang sebagai wisata outbound tidak hanya mendapatkan kemudahan saja, tentu banyak hal yang menjadi hambatan. Adapun hambatan yang terjadi yaitu ;

\section{Terbatasnya dana untuk melakukan promosi}

Bukit Naang ini merupakan sebuah perusahaan yg didirikan secara pribadi yang berbentuk CV (Comandiate Venootschap) adalah badan usaha yang didirikan oleh dua orang atau lebih, dimana salah satunya akan bertindak selaku persero aktif / pengurus, sedangkan yang lain akan bertindak sebagai persero komanditer / diam / sering juga disebut dengan pemilik / owner. Sejak awal pendirian perusaan ini pemerintah belum memperhatikan secara penuh objek wisata buatan ini. Tidak adanya dana yg lebih juga penyebab promosi kurang di terapkan oleh pihak pegelola.

\section{Tidak ada angkutan umum yang melewati antara jalan lintas menuju wahana di Taman Agro Wisata Bukit Naang}

Tidak ada angkutan umum yang melewati jalan lintas menuju Bukit $\mathrm{Na}$ 'ang, juga penghambat wisatawan perorangan yg tidak membawa kendaraan untuk masuk ke wahana permainan. Dari jalan lintas menuju wahana melalui hutan tropis yang panjangnya kurang lebih $2 \mathrm{~km}$. jika wisatawan tidak membawa kendaraan, maka mereka harus berjalan kaki untuk sampai ke wahana permainan di Bukit Naang.

\section{Promosi}

Bentuk promosi yang di lakukan oleh pemilik dan pengelola Bukit Na'ang ini lebih berpusat pada mulut ke mulut dan sosial media seperti Facebook, tweeter dan Blog yang mereka buat 
sendiri. Sedangkan promosi berupa pameran di Riau Expo pernah di lakukan, tetapi promosi bentuk pameran itu membutuhkan dana yang lebih dan tidak tepat sasaran.

\section{PEMBAHASAN}

Dari uraian tersebut di atas, maka dapat diketahui dalam mempromosikan objek wisata Taman Agro Wisata Bukit Naang sebagai wisata outbound di Kabupaten Kampar, strategi yang dilakukan oleh pihak pengelola Taman Agro Wisata Bukit Naang antara lain : Mengadakan pameran serta menyebarkan brosur kepada pengunjung; Dengan menggunakan media cetak, elektronik, sosial media dan blog; Informasi dari mulut ke mulut. Ada beberapa hal yang menjadi kendala bagi pengelola Taman Agro Wisata Bukit Naang Kabupaten Kampar dalam melaksanakan kegiatan kepromosiannya, yaitu : Terbatasnya dana untuk melakukan promosi; Waktu yang tidak tepat untuk melakukan promosi; Tidak adanya angkutan umum yang melewati jalan lintas menuju wahana di Taman Agro Wisata Bukit Naang; Kurang berjalannya promosi yang dilakukan; Tidak tepat nya sasaran promosi yang di lakukan.

Dengan ditemukannya beberapa hambatan dalam peningkatan kunjungan di Taman Agro Wisata Bukit Naang Kabupaten Kampar. Maka perlu beberapa upaya untuk mebuat wisatawan tertarik untuk mengunjungi wisata Outbound tersebut. Berikut ini adalah beberapa upaya mengatasi hambatan yang di lakukan pemilik dan pengelola Bukit Na'ang, antara lain adalah : Promosi memang telah di lakukan oleh pihak Pengelola dan pemilik Taman Agro Wisata Bukit Naang Kabupaten Kampar, tetapi jika tidak ada dukungan dari pihak pemerintah khususnya Dinas Pariwisata Propinsi Riau maka promosi bisa di katakan kurang maksimal. Oleh karena itu, hendaknya Dinas Pariwisata Propinsi Riau memberikan bantuan dalam betuk promosi tersebut, baik media cetak berupa brosur ataupun pameran dan media elektronik supaya promosi yang di lakukan oleh pihak pengelola tepat sasaran dan di dalam waktu yang tepat.

Kondisi ini didukung dengan konsep pemasaran pariwista merupakan kegiatan yang bertujuan untuk memperkenalkan produk pariwisata. Meliputi sejumlah kegiatan yang maksudnya untuk mempengaruhi, menghimbau, dam membujuk wisatawan potensial sebagai konsumen agar mengambil kepiutusan untuk mengadakan perjalanan. Pemasarn diartikan sebagai suatu reorientasi kebijakan usaha dan suatu pembenahan total dalam pemikiranpemikiran dasar dan penerapannya dalam organisasi atau badan usaha. Adapun tujuan dari pemasaran pariwisata Salah Wahab, (2000;150) adalh untuk memikat dan meyakinkan wisatawan bahwa daerah tujuan wisata yang tersedia dengan daya tarik, fasilitas, dan jasajasanya akan memenuhi selera mereka untuk datang.

Salah Wahab $(2000 ; 79)$ merumuskan pengertian pemasaran pariwisata sebagai proses manajemen dimana Organisasi Pariwisata Nasional (OPN) atau perusahaan kepariwisataan mengidentifikasikan wisatawan pilihan mereka, baik aktual maupun potensial, berkomunikasi dengan mereka untuk meyakinkan dan mempengaruhi keinginnan, kebutuhan, motifasi, kesenangan, maupu ketidak senangan mereka pada tingkat lokal, regional, nasional, maupun internasional, dan menyesuaikan produk wisatan mereka sesuai situasi agar wisatawan puas dengan memenuhi keinginan mereka.

Selanjutnya menurut Wahab $(2000 ; 109)$ pemasaran pariwisata di tandai oleh 3 ciri utama: Merupakan penawaran jasa-jasa. Dengan demikian apa yang ditawarkan itu tidak mungkin ditimbun dan harus dimanfaatkan dimana produk itu berada. Dengan kata lain mustahil mengangkatnya, dan oleh sebab itu produk tersebut berbeda dari produk-produk yang lain ditawarkan. Yang ditawarkan itu sifatnya kaku (frigid), dalam arti bahwa dalam usaha mengadakannya untuk keperluan wisata, sulit sekali untuk mengubah sasaran penggunaannya di 
luar pariwisata. Karena pariwisata belum menjadi kebutuhan pokok manusia, maka penawaran pariwisata harus bersaing ketat dengan penawaran barang-barang dan jasa-jasa lain.

\section{SIMPULAN}

Dalam mempromosikan objek wisata Taman Agro Wisata Bukit Naang sebagai wisata outbound di Kabupaten Kampar, strategi yang dilakukan oleh pihak pengelola Taman Agro Wisata Bukit Naang antara lain: Mengadakan pameran serta menyebarkan brosur kepada pengunjung; Dengan menggunakan media cetak, elektronik, sosial media dan blog; Informasi dari mulut ke mulut. Ada beberapa hal yang menjadi kendala bagi pengelola Taman Agro Wisata Bukit Naang Kabupaten Kampar dalam melaksanakan kegiatan kepromosiannya, yaitu: Terbatasnya dana untuk melakukan promosi; Waktu yang tidak tepat untuk melakukan promosi; Tidak adanya angkutan umum yang melewati jalan lintas menuju wahana di Taman Agro Wisata Bukit Naang; Kurang berjalannya promosi yang dilakukan; Tidak tepat nya sasaran promosi yang di lakukan.

Adapun usaha yang dilakukan oleh pengelola Taman Agro Wisata Bukit Naang di Kabupaten Kampar dalam mengetasi kendala yang ditemukan di wisata outbound dalam usaha mempromosikannya, yaitu: Memperbaiki pelayanan yang di berikan oleh pengurus dan karyawan yang ada di Taman Agro Wisata Bukit Naang; Mengadakan angkutan umum yang akan melewati antara jalan lintas untuk memasuki wahana Taman Agro Wisata Bukit Naang. Salah satu faktor yang mempengaruhi bagus atau tidaknya suatu wisata adalah karena adanya berbagai macam persepsi pengunjung itu sendiri. Semakin bagus pendapat yang diberikan, akan memberikan kesan yang bagus juga terhadap wisatawan tersebut. Dari hasil wawancara yang dilakukankebanyakan dari pengunjung mengatakan mereka puas terhadap pelayanan dan wahana yang da di Taman Agro Wisata Bukit Naang Kabupaten Kampar.

\section{DAFTAR PUSTAKA}

Alma, Buchari, 2000, Manajemen Pemasaran dan Pemasaran Jasa, Cetakan Pertama, Alfabeta., Jakarta.

Happy, Marpaung, 2002, Pengetahuan Kepariwisataan, Alfabeta, Bandung.

Hasan, Ali, 2008, Marketing Media Pressindo, Yogyakarta

Hornby, A S, 2000, Oxford Advanced Learners Dictionary, Sixth Edition, OUP, Oxford UK.

Kotler, Philip, 2005, Manajemen Pemasaran, Edisi Kesebelas, Jilid 2, PT Indeks Kelompok Gramedia, Jakarta.

Mardiyatama, 2006, Metode Penelitian Pariwisata, Andi, Yogyakarta.

Marriotti, 2006, Pengembangan Pariwisata, Andi, Yogyakarta.

Purnama, C.M Lingga, 2001, Strategy Marketing Plan, PT Gramaedia, Jakarta. 
Sofyan, Assauri, 2000, Manajemen Pemasaran Dasar Konsep dan Strategi, CV Rajawali, Jakarta.

Quirk, Radolph, 2003, Longman Dictionary of Contemporary English, University College, London.

Saladin, Djasmin, 2002, Manajemen Pemasaran, Linda Karaya. Bandung.

Sihite, Richard, 2000, Tourism Industry, PT Pradya Paramaita, Jakarta.

Simamora, Bilson, 2001, Memenangkan Pasar dengan Pemasaran Efektif dan Profitabel, PT Gramedia Pustaka Utama, Jakarta.

Simamora, Henry, 2001, Manajemen Pemasaran Internasional, PT Salemba Empat, Jakarta.

Smith, 2004, Perencanaan dan Pengembangan Pariwisata, Graha Ilmu, Yogyakarta.

Siswanto, Sutojo, 2001, Kerangka Manajemen Marketing Modern, Lembaga Pendidikan dan Pengembangan, PT Binaan, Jakarta.

Swasta, Basu, 2001, Pengantar Bisnis Modern, Edisi Kelima, Yogyakarta.

Tjipto, Fandi, 2002, Strategi Pemasaran, Andi, Yogyakarta.

Wahab, Salah, 2000, Pemasaran Pariwisata, PT Pradnya Paramita, Jakarta.

Yoeti, Oka A, 2000, Pengantar Ilmu Pariwisata, Angkasa, Bandung 